Editor's Note: These short reviews of recent JNeurosci articles, written exclusively by students or postdoctoral fellows, summarize the important findings of the paper and provide additional insight and commentary. If the authors of the highlighted article have written a response to the Journal Club, the response can be found by viewing the Journal Club at www.jneurosci.org. For more information on the format, review process, and purpose of Journal Club articles, please see http://jneurosci.org/content/ preparing-manuscript\#journalclub.

\title{
Alpha-Band Oscillation Mediates the Temporal Organization of Serially Presented Flashes
}

\author{
가고 Fan \\ School of Psychological and Cognitive Sciences, PKU-IDG/McGovern Institute for Brain Research, and Beijing Key Laboratory of Behavior and Mental \\ Health, Peking University, Beijing 100087, China \\ Review of Ronconi and Melcher
}

The visual system can perceive two distinct flashes presented sequentially as integrated or segregated, depending on the temporal interval between them (Hirsh and Sherrick, 1961; Kristofferson, 1967). Even when the two stimuli are presented with fixed interstimulus interval, however, behavioral performance on the integrated/segregated task is variable and modulated by brain oscillations, in particular the alpha rhythm $(8-12 \mathrm{~Hz})$. For example, higher alpha-band frequencies have been found to promote segregation of two flashes (Kristofferson, 1967; Cecere et al., 2015; Samaha and Postle, 2015), and the phase of alpha oscillation also affects the judgments of order or simultaneity (Varela et al., 1981; Gho and Varela, 1988).

In a recent publication in The Journal of Neuroscience, Ronconi and Melcher (2017) provided compelling evidence suggesting that ongoing oscillations, which were aligned and modified by sensory entrainment, play a critical role in temporal organization of perception. The task pro-

Received Dec. 26, 2017; revised Feb. 26, 2018; accepted March 1, 2018.

This work was supported by National Natural Science Foundation of China Grants 31522027 and 31571115. I thank my supervisor Dr. Huan Luo and my laboratory members Qiming Han, Jiaqi Li, and Jianrong Jia for helpful suggestions.

The author declares no competing financial interests.

Correspondence should be addressed to Ying Fan, School of Psycholog-

ical and Cognitive Sciences, Peking University, 52 Haidian Road, Beijing 100087, China. E-mail: yingfan1006@pku.edu.cn.

DOI:10.1523/JNEUROSCI.3633-17.2018

Copyright $\odot 2018$ the authors $\quad 0270-6474 / 18 / 383613-03 \$ 15.00 / 0$ cedure in this study included two main parts. First was an entrainment period in which synchronized audiovisual stimuli running at different frequencies were used to align participants' ongoing neuronal oscillations to those specific frequencies. In the first experiment, the entrainment frequency used for each participant was at either the lower $(8.5 \mathrm{~Hz})$ or upper $(11.5$ $\mathrm{Hz}$ ) boundary of the alpha rhythm. The second experiment recruited another group of participants, and each of them was entrained not only at the frequencies already used in the first experiment, but also at two additional frequencies in the theta $(6.5 \mathrm{~Hz})$ and beta $(14.5 \mathrm{~Hz})$ bands. After entrainment, participants performed a two-flash integration/segregation behavioral task, in which two flashes separated by a fixed short delay were presented, and participants were asked to report whether they perceived one or two flashes. To characterize perceptual fluctuations resulting from entrainment, the time duration/interval between the end of the entrainment sequence and the presentation of the leading flash in the behavioral task was varied between $\sim 6$ and $262 \mathrm{~ms}$ in the first experiment and between 25 and $250 \mathrm{~ms}$ in the second. Consequently, the first flash was presented at different phases of the oscillation (Fig. 1).

Via sorting all trials by the interval between the entrainment period end and the first flash presentation and calculating the two-flash rate (TFR), the proportion of times the participants reported seeing two separate flashes in the integration/segregation task, under each interval, a curve representing how the TFR fluctuated as a function of interval/time was obtained. This fluctuation of behavioral performance was termed as perceptual oscillation by Ronconi and Melcher (2017). Frequency analysis of the perceptual oscillation strongly suggested that the frequency of the entrainment could influence that of perceptual oscillation. Specifically, the peak frequency in the power spectrum of the perceptual oscillation depended on the entrainment frequency (e.g., $9.05 \mathrm{~Hz}$ for the $8.5 \mathrm{~Hz}$ entrainment and $10.86 \mathrm{~Hz}$ for the $11.5 \mathrm{~Hz}$ entrainment). Frequency analysis also showed that both above entrainment frequencies yielded a significant phase concentration, which means the onset points of perceptual oscillation at certain frequency range were concentrated to a small extent across all participants. Similar findings were exhibited in the second experiment when the entrainment frequency was extended to the high theta rhythm $(6.5 \mathrm{~Hz})$, but not to the beta band $(14.5 \mathrm{~Hz})$.

Although a link between the alphaband phase and the performance in the integration/segregation visual perception task was clearly demonstrated in the study by Ronconi and Melcher (2017), how the alpha-band phase determines the tempo- 


\section{A Explanation I (Time Window)}

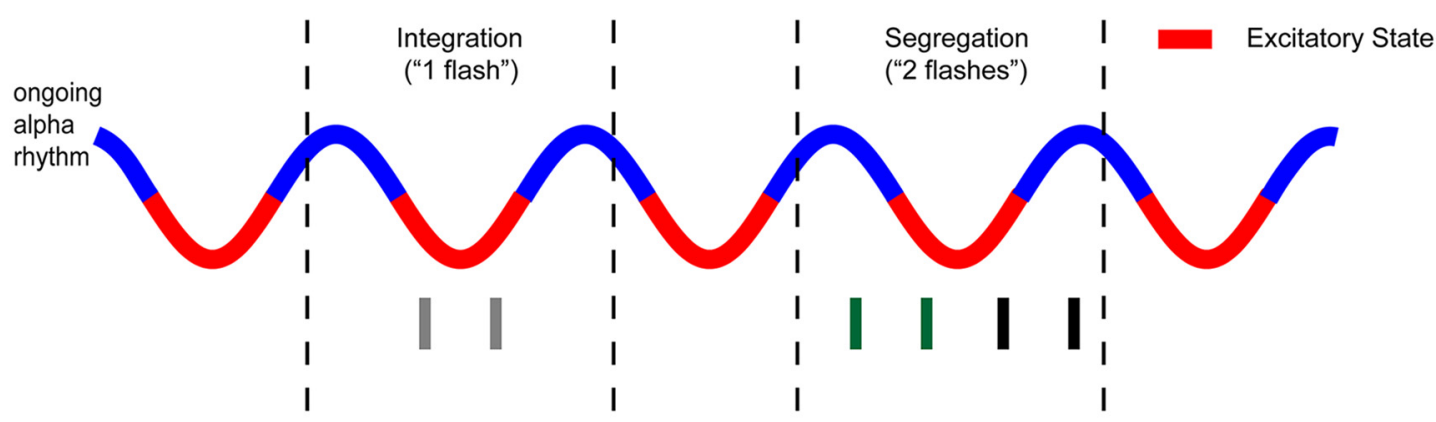

\section{B Explanation II (First-Flash-Perception)}

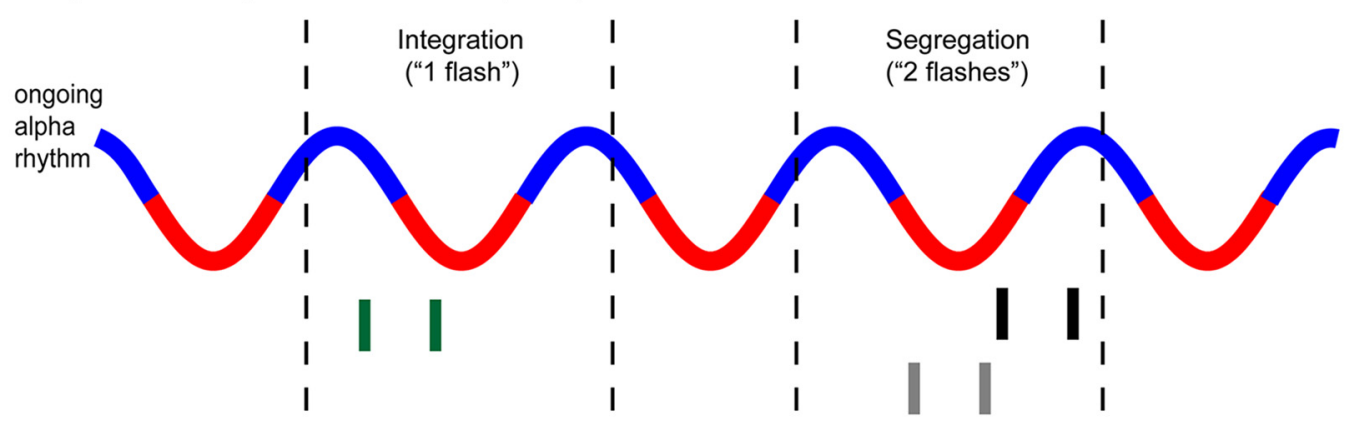

\section{Explanation III (Interflash Blank Perception)}

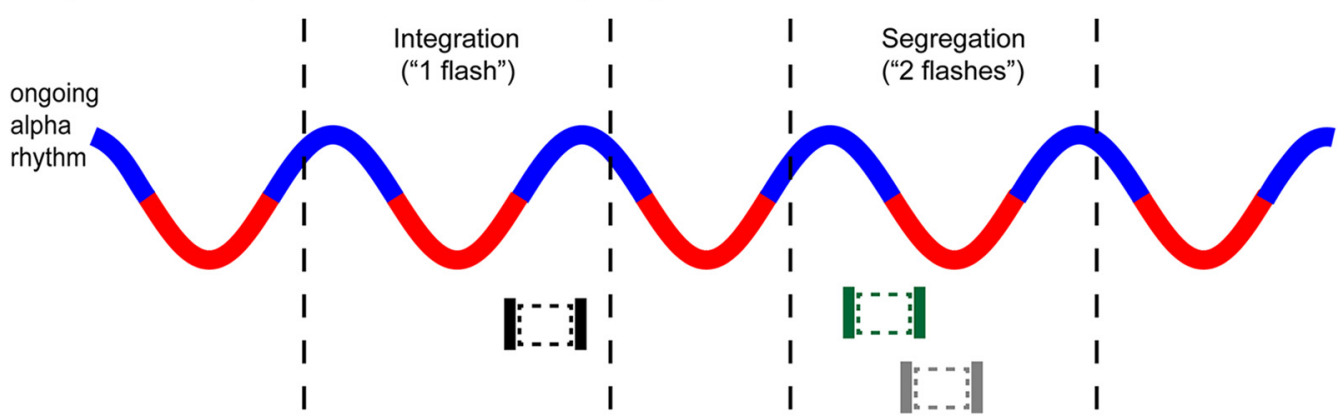

Figure 1. Illustrations of three possible explanations for the results of the study by Ronconi and Melcher (2017). $\boldsymbol{A}$, Time window hypothesis. Alpha cycle works as a discrete temporal window, within which two flashes are bound together as one flash and across which they are parsed as two flashes. $\boldsymbol{B}$, First-flash-perception hypothesis. If the first stimulus is presented in a phase associated with lower neural excitability level (blue), two flashes are perceived as one. If the first flash falls in an excitability phase (red), more accurate perception allows participants to perceive target flashes as two distinct events. C, Interflash blank perception interpretation. If the interflash blank largely falls in phases with lower excitability, it is less likely to be detected, allowing two flashes to be perceived as integrated. If the blank mostly falls in phases with higher excitability, the two flashes are perceived as segregated.

ral relationship of two flashes remains unclarified. Two possible mechanisms were proposed by the authors. One explanation is that the alpha cycle works as a discrete temporal window, within which two flashes are bound together as one flash and across which they are parsed as two flashes (Varela et al., 1981; VanRullen and Koch, 2003) (Fig. 1A). The other interpretation is built upon the fact that fluctuations of neural excitability are determined by alpha phase and, as a result, the alpha phase at which the first flash appeared might determine the results. If the first stimulus is presented in phases associated with lower neural excitability, it would be difficult to distinguish the two flashes. In contrast, if the first flash falls in the phases associated with higher excitability, processing of both targets as well as the interval would be improved, leading to a more accurate perception of them as two distinct events (Milton and Pleydell-Pearce, 2016) (Fig. 1B).

Notably, the two explanations as stated above result in contradictory predictions about the segregation/integration behavior (Fig. $1 A, B$ ), and both of them have some potential problems in explaining the results of Ronconi and Melcher (2017). According to the temporal window interpretation, the integration/segregation performance should fluctuate dramatically as a function of the interval (Milton and Pleydell-Pearce, 2016), but the observed deviation of the TFRs across all intervals is relatively small in the current study. The concern with the first-flash-perception interpretation is that alpha phase was mainly demonstrated to modulate the detection of near-threshold stimuli (Busch et al., 2009; Neuling et al., 2012). However, the contrast value of the target flashes was above threshold in the present study, which means that the target is expected to induce neural excitability sufficient to overcome the inhibitory effects of certain phases in alpha cycles, in which case flash detection would not be modulated by the ongoing alpha rhythm.

I would like to propose an alternative interpretation by focusing on the perceptual detection of the blank interval (i.e., 
between two flashes) and its involvement in integration/segregation performance (Fig. 1C). As stated by the authors, unlike the contrast value of target flashes, the time interval between two target flashes was set at a near threshold value to maximize perceptual alternations. Given that there is no difficulty in detecting two target flashes individually, perceiving them as simultaneous or asynchronous would presumably be determined by the ability to perceive the interval between them. Successful detection of the blank interval would lead to a "two flash" perception ("segregation"), whereas failure to perceive the blank interval would result in "one flash" perception ("integration"). It is widely believed that the trough of alpha oscillation is associated with the strongest release of neural inhibition, which would promote the processing of incoming stimuli (the blank screen in this case) (Jensen et al., 2012, 2014; Song et al., 2014; Jia et al., 2017). Thus, in the study by Ronconi and Melcher (2017), participants would be able to discriminate the two flashes only if a sufficient portion of the interflash blank interval was detected.

This explanation nicely aligns with the findings of Ronconi and Melcher (2017) in several aspects. One particular one is that the duration of the blank interval between two target flashes was $44 \mathrm{~ms}$, and the negative phase duration for $8.5 \mathrm{~Hz}$ and $11.5 \mathrm{~Hz}$ entrainment conditions was 59.5 $\mathrm{ms}$ and $43.5 \mathrm{~ms}$, respectively. Consequently, there is higher probability that the blank interval would fall in negative phases of the oscillations induced by the $8.5 \mathrm{~Hz}$ entrainment than by the $11.5 \mathrm{~Hz}$. Therefore, higher averaged TFR across all intervals would be found in the $8.5 \mathrm{~Hz}$ entrainment condition than in the $11.5 \mathrm{~Hz}$ entrainment condition, consistent with the experimental results. However, based on the current proposed explanation, theta (6.5
$\mathrm{Hz}$ ) entrainment with a wider window of negative phases was supposed to induce higher averaged TFR than alpha-band entrainment conditions, which is incongruent with the actual results in the Ronconi and Melcher (2017) study. The main reason for the absence of better overall discrimination performance for theta $(6.5 \mathrm{~Hz})$ entrainment is that the inhibitory mechanism is proved mainly specific to alphaband oscillations (Romei et al., 2010).

Overall, the study by Ronconi and Melcher (2017) provides strong evidence supporting the crucial role of the phase of the alpha-band oscillations in temporally organizing sequentially presented flashes. However, the mechanism underlying this effect (Fig. $1 A-C$ ) remains to be clarified. To address the issue, one possible approach could be considered in the future studies is to sample the integration/segregation at more temporal points after the entrainment sequence, and then comparing the performance when targets are presented in specific time points/phases, as demonstrated in Figure 1. In addition, a larger number of entrainment frequencies within and outside of the alpha range could be used to estimate whether the critical role of phase in temporal organization is specific to alpha-band oscillation or could be extended to other rhythms. These research directions would provide a deeper understanding of how the brain processes incoming information to perceive visual stimuli.

\section{References}

Busch NA, Dubois J, VanRullen R (2009) The phase of ongoing EEG oscillations predicts visual perception. J Neurosci 29:7869-7876. CrossRef Medline

Cecere R, Rees G, Romei V (2015) Individual differences in alpha frequency drive crossmodal illusory perception. Curr Biol 25:231235. CrossRef Medline

Gho M, Varela FJ (1988) A quantitative assessment of the dependency of the visual temporal frame upon the cortical rhythm. J Physiol (Paris) 83:95-101. Medline

Hirsh IJ, Sherrick CE Jr (1961) Perceived order in different sense modalities. J Exp Psychol 62:423-432. Medline

Jensen O, Bonnefond M, VanRullen R (2012) An oscillatory mechanism for prioritizing salient unattended stimuli. Trends Cogn Sci 16: 200-206. CrossRef Medline

Jensen O, Gips B, Bergmann TO, Bonnefond M (2014) Temporal coding organized by coupled alpha and gamma oscillations prioritize visual processing. Trends Neurosci 37:357369. CrossRef Medline

Jia J, Liu L, Fang F, Luo H (2017) Sequential sampling of visual objects during sustained attention. PLoS Biol 15:e2001903. CrossRef Medline

Kristofferson AB (1967) Successiveness discrimination as a two-state, quantal process. Science 158:1337-1339. CrossRef Medline

Milton A, Pleydell-Pearce CW (2016) The phase of pre-stimulus alpha oscillations influences the visual perception of stimulus timing. Neuroimage 133:53-61. CrossRef Medline

Neuling T, Rach S, Wagner S, Wolters CH, Herrmann CS (2012) Good vibrations: oscillatory phase shapes perception. Neuroimage 63: 771-778. CrossRef Medline

Romei V, Gross J, Thut G (2010) On the role of prestimulus alpha rhythms over occipitoparietal areas in visual input regulation: correlation or causation? J Neurosci 30:86928697. CrossRef Medline

Ronconi L, Melcher D (2017) The role of oscillatory phase in determining the temporal organization of perception: evidence from sensory entrainment. J Neurosci 37:1063610644. Medline

Samaha J, Postle BR (2015) The speed of alphaband oscillations predicts the temporal resolution of visual perception. Curr Biol 25: 2985-2990. CrossRef Medline

Song K, Meng M, Chen L, Zhou K, Luo H (2014) Behavioral oscillations in attention: rhythmic $\alpha$ pulses mediated through $\theta$ band. J Neurosci 34:4837-4844. CrossRef Medline

Varela FJ, Toro A, John ER, Schwartz EL (1981) Perceptual framing and cortical alpha rhythm. Neuropsychologia 19:675-686. CrossRef Medline VanRullen R, Koch C (2003) Is perception discrete or continuous? Trends Cogn Sci 7:207213. CrossRef Medline 